\title{
Palmitoleate inhibits insulin transcription by activating the ERK1/2 pathway in rat pancreatic $\beta$-cells
}

\author{
YUMEI YANG $^{1}$ and LIANGLIANG GONG ${ }^{2}$ \\ Departments of ${ }^{1}$ Endocrinology and Metabolism and ${ }^{2}$ Rheumatology, The Fourth Affiliated Hospital, \\ Zhejiang University School of Medicine, Yiwu, Zhejiang 322000, P.R. China
}

Received September 28, 2015; Accepted November 4, 2016

DOI: $10.3892 / e t m .2017 .4344$

\begin{abstract}
The aim of the present study was to evaluate the effects of palmitoleate on insulin secretion and insulin mRNA levels, and to investigate the transcriptional regulation of insulin. INS-1 rat insulinoma cells were treated with palmitoleate in the presence of high glucose, and the amount of secreted insulin was measured via radioimmunoassay. Reverse transcription-quantitative polymerase chain reaction was performed to evaluate the mRNA levels of insulin and pancreatic and duodenal homeobox 1 (PDX1) under palmitoleate treatment. The levels of PDX1, peroxisome proliferator-activated receptor gamma (PPARG), extracellular signal-regulated kinase (ERK)1/2 and phosphorylated ERK1/2 were measured using western blot analysis. Low concentrations of palmitoleate significantly induced insulin secretion ( $\mathrm{P}=0.024)$, whereas the mRNA levels of insulin and PDX1 were markedly reduced. However, the inhibitory effects were reversed with the addition of U0126, suggesting that the ERK1/2-mediated pathway may be the underlying mechanism responsible for palmitoleate-induced downregulation of insulin mRNA. Exposure of INS-1 cells to high glucose significantly increased the phosphorylation of ERK1/2 $(\mathrm{P}=0.039)$, which was further enhanced by palmitoleate $(\mathrm{P}=0.025)$. Exposure of INS-1 cells to high glucose significantly decreased PPARG $(\mathrm{P}=0.001)$, which was further decreased by the addition of palmitoleate. U0126 was able to reverse the palmitoleate-induced effects. In conclusion, the present study suggested that palmitoleate may induce insulin secretion and inhibit insulin mRNA expression in pancreatic $\beta$-cells.
\end{abstract}

Correspondence to: Dr Liangliang Gong, Department of Rheumatology, The Fourth Affiliated Hospital, Zhejiang University School of Medicine, 1 Shangcheng Road, Yiwu, Zhejiang 322000, P.R. China

E-mail: yangyumei66@yeah.net

Key words: palmitoleate, insulin, pancreatic and duodenal homeo box 1, extracellular signal-regulated kinase $1 / 2$, phosphorylated extracellular signal-regulated kinase $1 / 2$, phosphorylated-peroxisome proliferator-activated receptor gamma

\section{Introduction}

The incidence rates of metabolic dysfunctions such as diabetes, obesity, fatty liver disease and atherosclerosis are increasing, typically occurring together in the same individual and hence referred to as metabolic syndrome (1). Previous studies investigating these dysfunctions indicate that adipose tissue serves a key role in regulating the body's metabolism (2). Evidence suggests that adipose tissues in metabolic disorders produce peptides and hormones, which alter the normal homeostasis of lipids and carbohydrates. For example, in obese patients, fatty acids produced within adipose tissue may negatively impact peripheral tissues, contributing to hepatic steatosis or insulin resistance in muscles $(2,3)$. Various research models have revealed that lipid-mediated metabolic dysfunction is largely due to exposure to the lipids in adipose tissue $(2,3)$. The specific physiological and pathological roles of fatty acids vary depending on their chain length and degree of saturation, leading to differing effects on pancreatic $\beta$-cells (4).

Palmitate appears to be the most cytotoxic long-chain saturated fatty acid, whereas its monounsaturated equivalent, palmitoleate, is innocuous and protects $\beta$-cells against the toxicity of saturated fatty acids $(5,6)$. Dhayal et al (7) demonstrated that the cytoprotective effect of palmitoleate may be due to mediation by a fatty acid receptor rather than direct metabolic activation. Dimopoulos et al (8) reported that palmitoleate was able to promote the uptake and utilization of glucose in normal rat L6 skeletal muscle cells and those treated with the insulin resistance-inducing palmitate. Furthermore, levels of circulating palmitoleate exhibited a positive correlation with insulin sensitivity in humans (9).

Palmitoleate is considered to be a major signaling lipid hormone, regulating metabolic activities in multiple tissues, and serum fatty acid composition in response to changes in lipid metabolism in adipose tissue (10). However, the impact of palmitoleate on insulin secretion and intracellular expression in pancreatic $\beta$-cells, and therefore its role in insulin biology, remains to be elucidated. In the present study, the rat insulinoma cell line INS-1was used to examine the direct effects of palmitoleate on insulin secretion and intracellular insulin expression. It was revealed that palmitoleate-regulated insulin gene expression is associated with the extracellular signal-regulated kinase-1/2 (ERK1/2), peroxisome proliferator-activated receptor gamma (PPARG) and pancreatic and 
duodenal homeobox 1 (PDX1) signaling pathways. The results of the present study provided evidence that palmitoleate modulates insulin secretion and inhibits insulin mRNA expression.

\section{Materials and methods}

Antibodies and reagents. Rabbit-derived polyclonal antibody against PDX1 (cat. no. D59H3) and mouse-derived monoclonal antibodies against mitogen-activated protein kinase (MAPK; cat. no. 1150), phospho-MAPK-p44/42 ( $\mathrm{Thr}^{202} / \mathrm{Tyr}^{204}$; cat. no. 1150S) and PPARG (cat. no. D69) as well as the MEK1/2 inhibitor U0126 were obtained from Cell Signaling Technology, Inc. (Danvers, MA, USA). Palmitoleate was purchased from Sigma-Aldrich (Merck Millipore, Darmstadt, Germany) and dissolved in $90 \%$ ethanol at room temperature. Palmitoleate was bound to bovine serum albumin (BSA; Equitech-Bio, Inc., Kerrville, TX, USA) by mixing with a $10 \%$ solution of fatty acid-free bovine albumin at $37^{\circ} \mathrm{C}$ for $1 \mathrm{~h}$. For individual experiments, palmitoleate was added to Krebs-Ringer bicarbonate (KRB) buffer [Zen-Bio, Inc., Research Triangle Park, $\mathrm{NC}$, USA; comprising $135 \mathrm{mM} \mathrm{NaCl}, 3.6 \mathrm{mM} \mathrm{KCl}, 10 \mathrm{mM}$ HEPES (pH 7.4), $0.5 \mathrm{mM} \mathrm{MgCl}, 1.5 \mathrm{mM} \mathrm{CaCl}, 0.5 \mathrm{mM}$ $\mathrm{NaH}_{2} \mathrm{PO}_{4}$ and $2 \mathrm{mM}$ L-glutamine] containing $0.5 \%$ ethanol and $1 \%$ BSA to yield appropriate final concentrations $(0,0.05$, $0.1,0.2,0.3,0.4$ or $0.5 \mathrm{mM}$ ) as described previously (11). Insulin radioimmunoassay (RIA) kits (Rat Insulin RIA; cat. no. RI-13 K) were from Linco Research, Inc. (St. Charles, MO, USA). All chemicals were of analytical grade.

Cells and culture. The rat insulinoma cell line INS-1 was obtained from the China Center for Type Culture Collection (Wuhan University, Wuhan, China). RPMI-1640 cell culture medium and fetal bovine serum (FBS) were purchased from HyClone (GE Healthcare Life Sciences, Logan, UT, USA).

INS-1 cells were maintained in RPMI-1640 medium containing $11 \mathrm{mM}$ glucose supplemented with $10 \%(\mathrm{v} / \mathrm{v})$ heat-inactivated FBS, $100 \mathrm{U} / \mathrm{ml}$ penicillin, $100 \mathrm{U} / \mathrm{ml}$ streptomycin, $10 \mathrm{mM}$ HEPES, $1 \mathrm{mM}$ sodium pyruvate and $50 \mu \mathrm{M}$ $\beta$-mercaptoethanol (all Takara Biotechnology Co., Ltd., Dalian, China). Culture medium was replaced daily until cell confluency reached $80-90 \%$.

Measurement of insulin secretion and intracellular insulin content. INS- 1 cells were seeded in 24 -well plates and maintained in medium containing $5.5 \mathrm{mM}$ of glucose for $16 \mathrm{~h}$ one day prior to the experiment. Cells were subsequently serum-starved in medium containing $0.5 \%$ BSA for $2 \mathrm{~h}$, prior to being maintained in $\mathrm{KRB}$ buffer containing $115 \mathrm{mM} \mathrm{NaCl}$, $5 \mathrm{mM} \mathrm{KCl}, 24 \mathrm{mM} \mathrm{NaHCO} 3,2.5 \mathrm{mM} \mathrm{CaCl}_{2}, 1 \mathrm{mM} \mathrm{MgCl}{ }_{2}$, $10 \mathrm{mM}$ HEPES and $0.1 \%$ BSA for $24 \mathrm{~h}$. Cells were incubated in KRB in the presence of various concentrations $(0,0.05,0.1$, $0.2,0.3,0.4$ and $0.5 \mathrm{mM}$ ) of palmitoleate and insulin concentrations in the KRB buffer were measured using a rat insulin RIA kit. Plates were then washed once with PBS, intracellular insulin was extracted with $150 \mu 1$ acid ethanol [a 140:57:3 $(\mathrm{v} / \mathrm{v} / \mathrm{v})$ solution of ethanol/water/concentrated $\mathrm{HCl}]$ and the insulin content was determined via RIA, using rat insulin as the standard. For pharmacological inhibition of MEK1/2, cells were treated with $10 \mu \mathrm{M}$ of $\mathrm{U} 0126$ for 30 min prior to palmitoleate treatment.
RNA extraction and reverse transcription-quantitative polymerase chain reaction (RT- $q P C R)$. The acid guanidinium thiocyanate-phenol-chloroform extraction procedure (10) was used for the extraction of total RNA from INS- 1 cells. The quantity and quality of the extracted RNA was confirmed by absorption measurement at 260 and $280 \mathrm{~nm}$ using a U-2000A spectrophotometer (Hitachi, Ltd., Tokyo, Japan). The prepared RNA $(10 \mu \mathrm{g})$ was mixed with $500 \mathrm{pmol}$ of the oligo dT primer for $15 \mathrm{~min}$ at $68^{\circ} \mathrm{C}$. The RNA sample was reverse-transcribed at $37^{\circ} \mathrm{C}$ for 15 min into first-strand cDNA in RT solution performed with $5 \mu 15 \mathrm{X}$ PrimeScript buffer, $1 \mu \mathrm{l}$ PrimeScript RT Enzyme Mix I, 1 ul Oligo dT Primer $(50 \mu \mathrm{M}), 1.5 \mu 1$ random 6-mers $(100 \mu \mathrm{M})$ and $1 \mu 1$ total RNA (PrimeScript RT reagent kit; Takara Biotechnology Co., Ltd), with a total volume of $25 \mu 1$. RT-qPCR was performed using an ABI 7000 sequence detection system (Applied Biosystems; Thermo Fisher Scientific, Inc., Waltham, MA, USA). TaqMan gene expression assays were performed in accordance with the manufacturer's instructions (SYBR Premix Ex Taq; Takara Biotechnology Co., Ltd.). Primers and probes (Takara Biotechnology Co., Ltd.) used for RT-qPCR are listed in Table I. qPCR, which was optimized for a final reaction volume of $20 \mu 1$, was performed with $10 \mu 1$ SYBR Premix Ex Taq, $7 \mu 1$ nuclease-free water, $1 \mu \mathrm{l}$ forward primer $(10 \mu \mathrm{M}), 1 \mu \mathrm{l}$ reverse primer $(10 \mu \mathrm{M})$ and $1 \mu \mathrm{l}$ cDNA template. Amplification was performed under the following conditions: INS $-1,94^{\circ} \mathrm{C}$ for $2 \mathrm{~min}$, followed by 30 cycles of $94^{\circ} \mathrm{C}$ for $15 \mathrm{sec}$ and $63^{\circ} \mathrm{C}$ for $1 \mathrm{~min}$; PDX-1, $94^{\circ} \mathrm{C}$ for $2 \mathrm{~min}$, followed by 40 cycles of $94^{\circ} \mathrm{C}$ for $15 \mathrm{sec}$ and $63.5^{\circ} \mathrm{C}$ for $1 \mathrm{~min}$; actin, $94^{\circ} \mathrm{C}$ for $2 \mathrm{~min}$, followed by 25 cycles of $94^{\circ} \mathrm{C}$ for $15 \mathrm{sec}$ and $59^{\circ} \mathrm{C}$ for $1 \mathrm{~min}$. PCR amplification of GAPDH mRNA was conducted according to the manufacturer's instructions for the TaqMan GAPDH control reagent. Experiments were performed in triplicate and the results of the RT-qPCR were calculated using the $2^{-\Delta \Delta C q}$ method with minor revisions (12).

Western blot analysis. Cells were lysed with sodium dodecyl sulfate (SDS) lysis buffer (Beyotime Institute of Biotechnology, Haimen, China), and $50 \mu \mathrm{g}$ extracted proteins per lane were separated by $10 \%$ SDS-PAGE. Fractionized proteins were transferred to polyvinylidene fluoride (PVDF) membranes (Immobilon-P; Merck Millipore). Immunoblotting was performed by incubating the PVDF membrane in TBS buffer containing $0.1 \%$ Tween and 5\% non-fat milk for $1 \mathrm{~h}$ at $4^{\circ} \mathrm{C}$, followed by overnight incubation at $4^{\circ} \mathrm{C}$ with antibodies against pERK1/2 $\left(\mathrm{Thr}^{202} / \mathrm{Tyr}^{204} ; 1: 1,000\right.$ dilution) or total ERK1/2 (1:1,000), PDX1 (1:750), PPARG (1:500), and $\beta$-actin $(1: 5,000)$, respectively. Signals were detected and visualized using a horseradish peroxidase-labeled anti-rabbit antibody (1:5,000; cat. no. 166-2408-MSDS; Bio-Rad Laboratories, Inc., Hercules, CA, USA) and enhanced chemiluminescence using the FluorChem Q system (ProteinSimple, San Jose, CA, USA). The signals were normalized using AlphaView image analysis software 2.0 (ProteinSimple). Experiments were performed in triplicate.

Statistical analysis. Values are expressed as the mean \pm standard error of the mean. Differences were analyzed using one-way analysis of variance. Where appropriate, Student's $t$-test was used for the comparison of two treatments. $\mathrm{P}<0.05$ 
Table I. Sequence of polymerase chain reaction primers (5'-3').

\begin{tabular}{|c|c|c|c|c|}
\hline Gene & Sense primer & Anti-sense primer & Size (bp) & Accession no. \\
\hline Ins 1 & GCTCTGTACCTGGTGTGTGG & GTGCCAAGGTCTGAAGAT & 114 & NM_019129.3 \\
\hline Pdx1 & GAACCGGAGGAGAATAAGAGG & AGTCAAGTTGAGCATCACTGC & 115 & NM_022852.3 \\
\hline$\beta$-actin & CATGCATGACGATATCGCTGC & GTACGACCAGAGGCATACAGG & 424 & NM_031144.2 \\
\hline
\end{tabular}

PDX1, pancreatic and duodenal homeobox 1 .
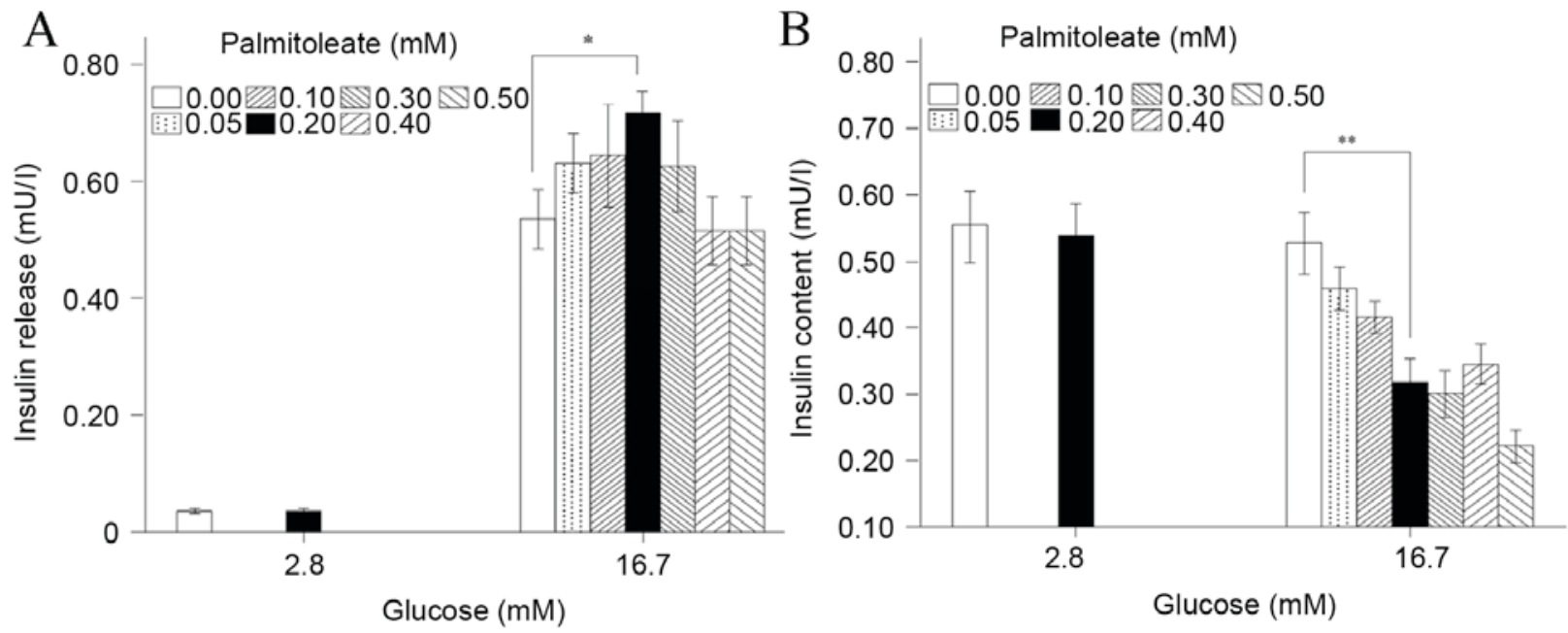

Figure 1. Palmitoleate differentially impacts insulin secretion and expression. INS-1 cells $\left(\mathrm{n}=2 \times 10^{5}\right)$ were pre-treated with low $(2.8 \mathrm{mM})$ or high glucose $(16.7 \mathrm{mM})$, and different doses of palmitoleate were introduced for $24 \mathrm{~h}$. (A) Insulin secretion in medium and (B) intracellular insulin content were measured via radioimmunoassay. Results were expressed as the mean of six independent experiments \pm standard error of the mean and a two-way analysis of variance was performed. ${ }^{*} \mathrm{P}<0.05,{ }^{* *} \mathrm{P}<0.01$.

was considered to indicate a statistically significant difference, as calculated using SPSS 13.0 (SPSS, Inc., Chicago, IL, USA).

\section{Results}

Palmitoleate impacts insulin secretion and intracellular content. In the present study, $2 \times 10^{5}$ normalized INS-1 cells were treated in the presence of 2.8 or $16.7 \mathrm{mM}$ glucose with or without palmitoleate, and the amount of insulin secreted into the culture medium and the intracellular insulin content were measured. Under low-glucose conditions (2.8 mM), $0.2 \mathrm{mM}$ palmitoleate caused no significant changes to insulin secretion into the medium or the cellular insulin content (Fig. 1A and B). However, in the presence of high glucose $(16.7 \mathrm{mM})$, the effect of palmitoleate on insulin secretion in the medium appeared to be dependent on its concentration, with the maximal effect at $0.20 \mathrm{mM}$ to achieve a statistically significant increase by $34 \%$ vs. the control (i.e., $0 \mathrm{mM}$ palmitoleate; $\mathrm{P}=0.024$; Fig. 1A). Under the same conditions, the intracellular insulin content in INS-1 cells decreased significantly by $40 \%$ vs. the control ( $\mathrm{P}=0.007$; Fig. 1B). These results indicated that under high-glucose conditions, the expression of insulin may be inhibited by palmitoleate treatment, although palmitoleate within a certain concentration range (around $0.20 \mathrm{mM}$ ) can promote insulin secretion. The palmitoleate-treated total insulin (insulin release and insulin content) was significantly decreased compared with that observed with no palmitoleate-treatment in high glucose $(\mathrm{P}=0.039$; data not shown).

Palmitoleate decreases insulin mRNA levels in a dose-dependent manner. The observation that palmitoleate inhibited the intracellular insulin content in a dose-dependent manner suggested that palmitoleate may modulate insulin mRNA levels. To investigate this, insulin mRNA levels in rat INS-1 cells were measured in response to different final concentrations of palmitoleate (0.05-0.5 mM) using RT-qPCR. The results showed that palmitoleate significantly decreased insulin mRNA levels in a dose-dependent manner $(\mathrm{P}=0.011$; Fig. 2).

Palmitoleate elevates high glucose-induced ERK1/2 phosphorylation in INS-1 cells. The phosphorylation level of ERK1/2 (pERK1/2), which is an intracellular kinase activated by various cytokines and chemokines, was evaluated to elucidate the mechanism by which insulin mRNA levels are downregulated in response to high glucose and palmitoleate. As demonstrated in Fig. 3, exposure of INS-1 cells to high glucose (16.7 mM) significantly increased ERK1/2 phosphorylation in comparison with low glucose $(2.8 \mathrm{mM} ; \mathrm{P}=0.039)$. Furthermore, with the addition of $0.2 \mathrm{mM}$ palmitoleate, pERK1/2 was significantly increased $(P=0.025)$ in cells exposed to high glucose. However, when the specific ERK1/2 


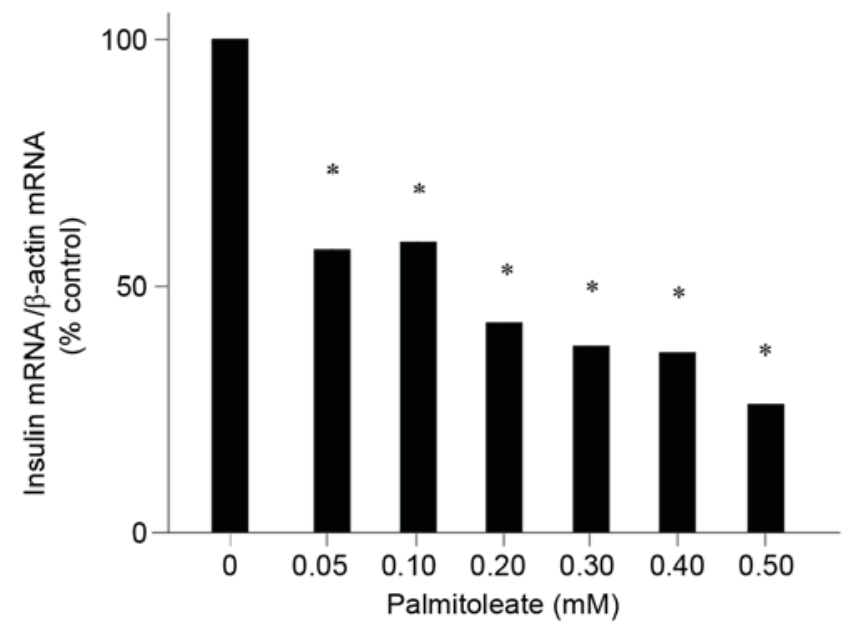

Figure 2. Palmitoleate decreases insulin mRNA levels in a dose-dependent manner. INS-1 cells maintained in high glucose $(16.7 \mathrm{mM})$ were treated with palmitoleate at different final concentrations for $24 \mathrm{~h}$. Cells were then harvested and total RNA was extracted. Reverse transcription-quantitative polymerase chain reaction was performed to amplify insulin and $\beta$-actin mRNA. The relative insulin mRNA changes were normalized to $\beta$-actin. Results were expressed as the means \pm standard error of the mean of three experiments and a one-way analysis of variance was performed. ${ }^{*} \mathrm{P}<0.05$ vs. $0 \mathrm{mM}$ palmitoleate.
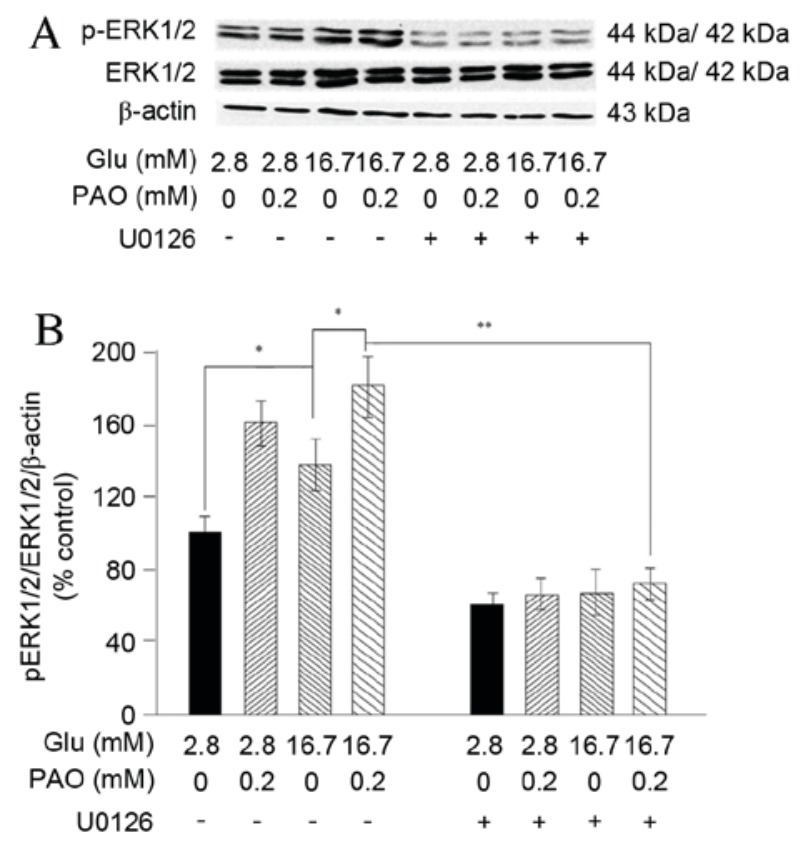

Figure 3. Treatment with high glucose and palmitoleate increased ERK1/2 phosphorylation in INS-1 cells. INS-1 cells maintained in indicated glucose concentrations were treated with $0.2 \mathrm{mM}$ palmitoleate for $24 \mathrm{~h}$, or U0216 (final concentration $10 \mu \mathrm{M}$ ) for $30 \mathrm{~min}$, followed by palmitoleate for $24 \mathrm{~h}$. (A) Cells were then harvested, lysed and $50 \mu \mathrm{g}$ extracted crude proteins were subjected to $10 \%$ SDS-PAGE followed by western blot analysis to examine pERK1/2, ERK1/2 and $\beta$-actin. (B) Relative signal intensity was normalized to $\beta$-actin. Results were expressed as the mean \pm standard error of the mean of three experiments and a two-way analysis of variance was carried out. ${ }^{*} \mathrm{P}<0.05,{ }^{* *} \mathrm{P}<0.01$. ERK, extracellular signal-regulated kinase; $\mathrm{p}$, phosphorylated; glu, glucose; PAO, palmitoleate.

inhibitor U0126 was introduced, the effects of palmitoleate were significantly reduced $(\mathrm{P}=0.002)$. This further supported the hypothesis that palmitoleate elevates ERK1/2 activation and suggested that the activation of ERK1/2 may be the mechanism underlying the response elicited by palmitoleate.

Palmitoleate reduces increases in high glucose-induced PDX1 mRNA in INS-1 cells. Palmitate has been previously shown to inhibit insulin gene expression by decreasing PDX1 nuclear exclusion in MIN6 cells, and PDX1 serves a crucial role in the control of insulin gene expression in pancreatic $\beta$-cells $(13,14)$. To further explore the possible molecular mechanisms by which PDX1 is associated with palmitoleate-mediated inhibition of insulin expression in INS-1 cells, PDX1 mRNA levels following glucose and palmitoleate treatments in the absence or presence of U0126 were assessed. Although a 24-h exposure to high glucose $(16.7 \mathrm{mM})$ induced a significant increase in PDX1and insulin mRNA levels $(\mathrm{P}=0.001)$, the addition of palmitoleate significantly reduced these effects $(\mathrm{P}=0.001$; Fig. 4A and B). Furthermore, when U0126 was introduced, the inhibition of PDX1 and insulin mRNA levels was reversed (Fig. 4A and B).

Palmitoleate reduces increases in high glucose-induced PPARG and PDX1 expression in INS-1 cells. PPARG has been demonstrated to serve a role in PDX1 mRNA expression and the transcriptional activity of PPARG is inhibited by MAPK-mediated phosphorylation of PPARG at Ser84 (15-17). This suggests that PPARG activation is an upstream event that regulates the status of PDX1 upon treatment with palmitoleate. In the present study, exposure of INS-1 cells to high glucose $(16.7 \mathrm{mM})$ significantly decreased PPARG and increased PDX1 expression $(\mathrm{P}<0.005$ for each), while addition of palmitoleate caused significant decreases $(\mathrm{P}<0.005$; Fig. 5). As PPARG increased, PDX1 expression increased correspondingly.

Palmitoleate activates the ERK1/2 pathway in INS-1 cells under high-glucose treatment. The observation that $0.2 \mathrm{mM}$ palmitoleate increased insulin secretion (Fig. 2) and activated ERK1/2 phosphorylation in INS-1 cells under high glucose conditions (Fig. 3) indicated that phosphorylation of ERK1/2 may be the mechanism underlying palmitoleate-mediated insulin secretion. To investigate this further, insulin secretion into the medium and cellular insulin content in the normalized INS-1 cells was measured following the addition of U0126. Consistent with the previous results, under high glucose conditions, $0.2 \mathrm{mM}$ palmitoleate significantly promoted insulin secretion $(\mathrm{P}=0.001)$, whereas intracellular insulin levels were markedly reduced. When ERK1/2 phosphorylation was blocked via the introduction of U0126, the secretion of insulin was significantly elevated $(\mathrm{P}=0.001$; Fig. $6 \mathrm{~A})$ and the decrease in intracellular content of insulin was significantly reversed $(\mathrm{P}=0.001$; Fig. $6 \mathrm{~B})$. These results suggested that the activation of the ERK1/2 pathway is associated with palmitoleate-mediated cellular processes and functions as a mediator of the effect of palmitoleate treatment on insulin. Furthermore, in high glucose conditions, the total insulin (insulin released and cellular insulin content) was significantly increased following palmitoleate and U0126 treatment compared with that observed following treatment with only palmitoleate $(\mathrm{P}=0.027$; data not shown). 

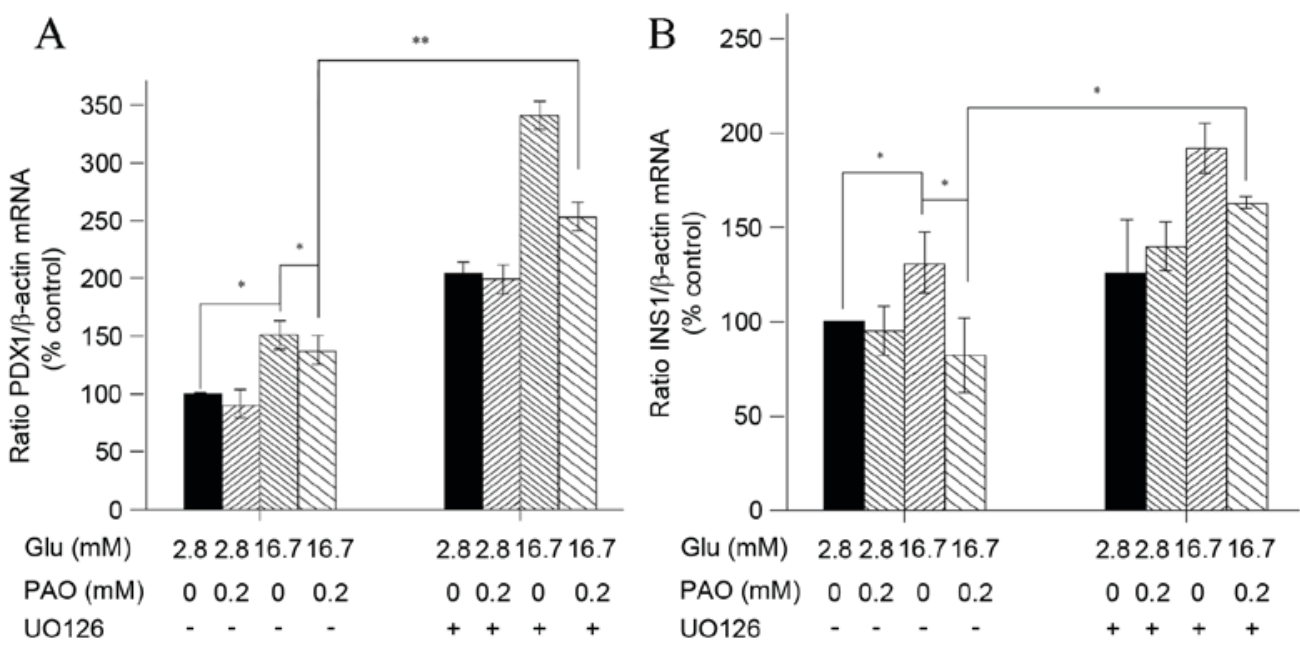

Figure 4. Treatment with high glucose and palmitoleate decrease PDX1 mRNA level in INS-1 cells. INS-1 cells maintained in indicated glucose concentrations were treated with $0.2 \mathrm{mM}$ palmitoleate for $24 \mathrm{~h}$, or U0216 (final concentration $10 \mu \mathrm{M}$ ) for $30 \mathrm{~min}$, followed by palmitoleate for $24 \mathrm{~h}$. Cells were subsequently harvested and total RNA was extracted. Reverse transcription-quantitative polymerase chain reaction was performed to amplify PDX1. (A) The relative PDX1 mRNA changes were normalized to $\beta$-actin. (B) The relative Ins1 mRNA changes were normalized to $\beta$-actin. Results were expressed as the means \pm standard error of the mean of three experiments and a two-way analysis of variance was performed. "P $<0.05,{ }^{* *} \mathrm{P}<0.01$. PDX, pancreatic and duodenal homeobox protein; Ins1, insulin; PAO, palmitoleate.
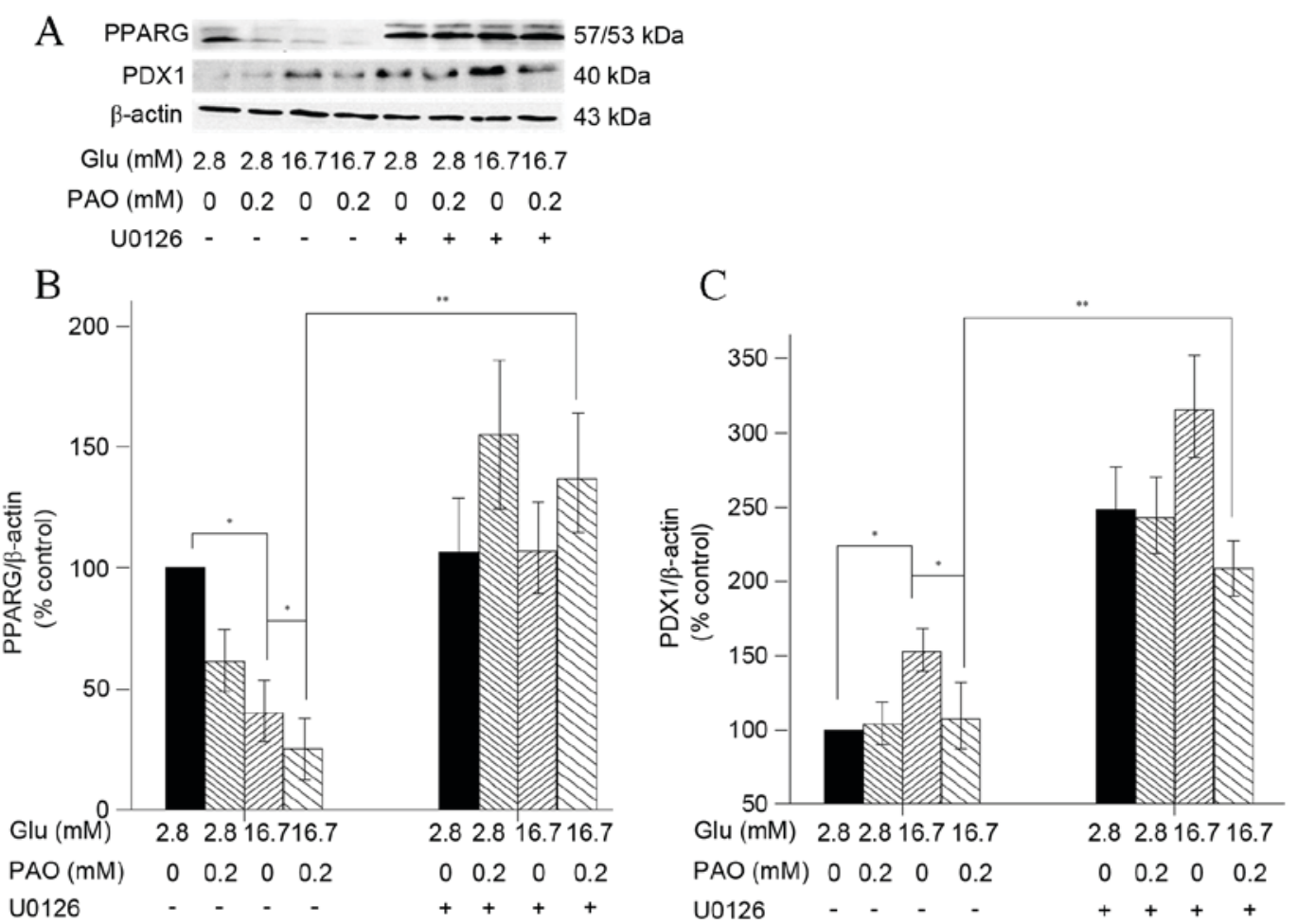

Figure 5. Treatment with high glucose and palmitoleate decreases PPARG and PDX1 expression in INS-1 cells. INS-1 cells maintained in indicated glucose concentrations were treated with $0.2 \mathrm{mM}$ palmitoleate for $24 \mathrm{~h}$, or U0216 (final concentration $10 \mu \mathrm{M}$ ) for $30 \mathrm{~min}$, followed by palmitoleate for $24 \mathrm{~h}$. (A) Cells were then harvested, lysed and 50 ug extracted crude proteins were subjected to 10\% SDS-PAGE followed by western blot analysis to examine PPARG, PDX1 and $\beta$-actin. (B) Relative signal intensity of PPARG was normalized to $\beta$-actin. (C) Relative signal intensity of PDX1 was normalized to $\beta$-actin. Results were expressed as the means \pm standard error of the mean of three experiments and a two-way analysis of variance was performed. "P<0.05, ${ }^{* * *} \mathrm{P}<0.01$ compared with corresponding controls. PPARG, peroxisome proliferator-activated receptor gamma; PDX, pancreatic and duodenal homeobox protein; Glu, glucose; PAO, palmitoleate.

\section{Discussion}

Palmitoleate is a newly identified adipokine that has various insulin-associated effects, including the stimulation of uptake and utilization of glucose in normal and insulin-resistant skeletal muscle cells, improvement of insulin resistance $(8,9)$, suppression of lipid cytotoxicity and apoptosis induced by saturated fatty acids in pancreatic $\beta$-cells (10), inhibition 

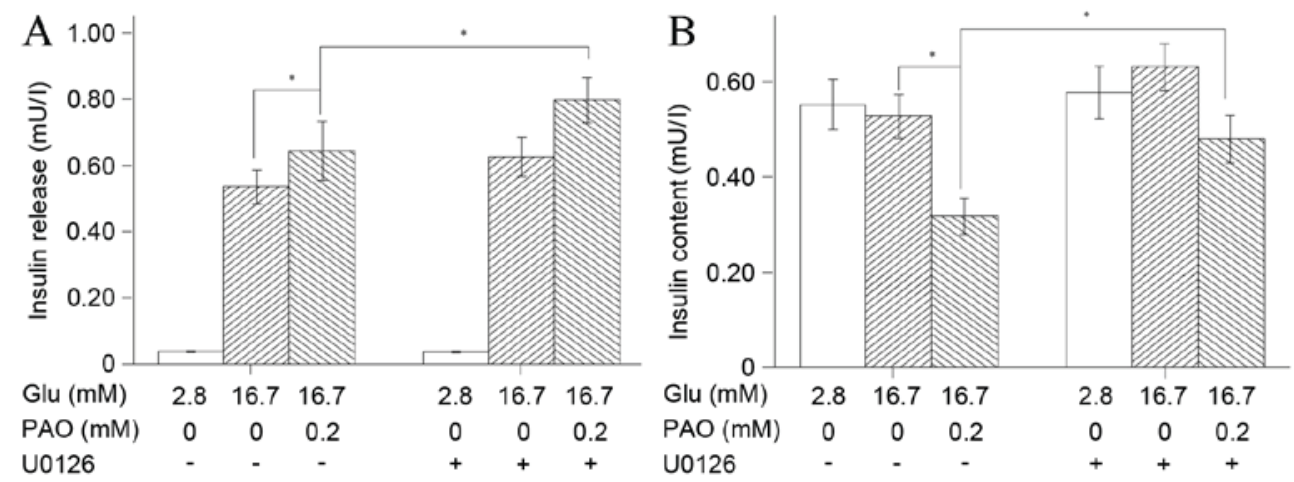

Figure 6. Inhibition of ERK1/2 facilitates insulin secretion and increases intracellular insulin content in INS-1 cells. INS-1 cells $\left(\mathrm{n}=2 \times 10^{5}\right)$ were pre-treated with low glucose $(2.8 \mathrm{mM})$ or high glucose $(16.7 \mathrm{mM})$, and then $0.2 \mathrm{mM}$ palmitoleate was introduced for $24 \mathrm{~h}$ in the absence or presence of U0126. (A) Insulin secretion in the medium and (B) intracellular insulin content were measured via radioimmunoassay. Results were expressed as the mean of six independent experiments \pm standard error of the mean and a two-way analysis of variance was performed. "P $<0.05$. ERK, extracellular signal-regulated kinase; Glu, glucose; PAO, palmitoleate.

of liver steatosis (10) and depression of adipose inflammation (13). However, the signaling pathways associated with the regulation of insulin mRNA levels in response to palmitoleate are yet to be elucidated.

It has been demonstrated that free fatty acid-induced insulin secretion is glucose-dependent, and that at elevated concentrations of extracellular glucose, free fatty acids will further amplify glucose-mediated insulin secretion (14-17). The present study demonstrated that the free fatty acid palmitoleate differentially regulates insulin secretion and insulin mRNA levels in the rat-derived insulin-producing cell line INS-1and rat pancreatic islets (18). Palmitoleate treatment induced an increase in insulin secretion under high glucose conditions, while its effect under low glucose conditions was minor, indicating that the glucose concentration influences insulin expression mediated by palmitoleate treatment. Although the underlying mechanisms remain to be elucidated, changes in the ERK1/PPAR/PDX1 signaling pathway were observed in the present study. A 24-h exposure of INS-1 cells to $0.05-0.5 \mathrm{mM}$ palmitoleate induced a dose-biphasic increase in glucose-stimulated insulin secretion with a maximum effect at $0.2 \mathrm{mM}$. Conversely, $0.2 \mathrm{mM}$ palmitoleate inhibited insulin gene expression at a high glucose concentration by impairing the glucose-induced increase in insulin mRNA levels. The $0.2 \mathrm{mM}$ concentration was subsequently used to investigate the underlying mechanisms of the insulin secretion response to palmitoleate stimulation.

It is well known that $\mathrm{G}$ proteins dissociate into the free subunits $G_{\alpha}$ and $G_{\beta \gamma}$ upon receptor activation, with the two components leading to different cellular signaling events (19). In the example of $G$ protein-coupled mitogen, $G_{\beta \gamma}$ mediates the intracellular signaling pathway, which facilitates cell proliferation by activating $\mathrm{p} 21^{\text {ras }}$, which in turn activates $\mathrm{p} 42$ and MAPKs (20). The present study revealed that palmitoleate increases glucose-induced ERK1/2 phosphorylation and decreases glucose-induced PDX1 expression as well as PPARG expression. Furthermore, inhibition of ERK $1 / 2$ potentiated the expression of PDX1, insulin mRNA and PPARG.

Previous studies have demonstrated that the transcriptional activity of PPARG is suppressed by phosphorylation of Ser82 mediated by MAPK $(21,22)$, and the results of the present study are consistent with this conclusion. It has been previously shown that in INS-1 cells, elevated PPARG promotes PDX1 transcription and expression $(23,24)$, suggesting that the activation of PPARG is an upstream event regulating PDX1. In the present study, it was also demonstrated that the inhibition of PPARG was associated with decreased PDX1 mRNA levels and protein expression and that these effects may also be reversed by the ERK $1 / 2$ inhibitor U0126. Together, these results suggested that the ERK1/2, PPARG and PDX1 signaling pathways are implicated in the inhibitory effects of palmitoleate on insulin gene expression.

In the present study, it was demonstrated that the adipose tissue-derived hormone palmitoleate acts directly on pancreatic $\beta$-cells. The strongest induction of insulin release in INS-1 cells in the presence of high glucose was observed with a $0.2 \mathrm{mM}$ palmitoleate treatment for $24 \mathrm{~h}$. The results of the present study revealed the association of the ERK1/2, PPARG and PDX1 pathways in palmitoleate-mediated inhibition of glucose-induced insulin gene expression in INS-1 cells. While it remains to be determined whether the mechanisms in humans are similar, the present study may be clinically significant: If elevation of the palmitoleate concentration is able to improve insulin resistance and stimulate insulin release, the inhibitory effects on intracellular insulin expression should be taken into account. In vivo experiments to evaluate the effects of palmitoleate on insulin secretion and expression in pancreatic $\beta$-cells are currently underway.

In conclusion, the present study revealed that high glucose-induced phosphorylation of ERK1/2 is able to facilitate insulin transcription, which may be inhibited by palmitoleate. However, palmitoleate may exert its effects via multiple pathways.

\section{Acknowledgements}

The present study was supported by a grant from the Medical Science and Technology Project of Zhejiang Province (no. 2014KYA129). 


\section{References}

1. Eckel RH, Grundy SM and Zimmet PZ: The metabolic syndrome. Lancet 365: 1415-1428, 2005.

2. Ginsberg HN, Zhang YL and Hernandez-Ono A: Metabolic syndrome: Focus on dyslipidemia. Obesity (Silver Spring) 14 (Suppl 1): S41-S49, 2006

3. Bergman RN and Ader M: Free fatty acids and pathogenesis of type 2 diabetes mellitus. Trends Endocrinol Metab 11: 351-356, 2000.

4. Newsholme P, Keane D, Welters HJ and Morgan NG: Life and death decisions of the pancreatic beta-cell: The role of fatty acids. Clin Sci (Lond) 112: 27-42, 2007.

5. Diakogiannaki E, Dhayal S, Childs CE, Calder PC, Welters HJ and Morgan NG: Mechanisms involved in the cytotoxic and cytoprotective actions of saturated versus monounsaturated long-chain fatty acids in pancreatic beta-cells. J Endocrinol 194: 283-291, 2007.

6. Welters HJ, Tadayyon M, Scarpello JH, Smith SA and Morgan NG Mono-unsaturated fatty acids protect against beta-cell apoptosis induced by saturated fatty acids, serum withdrawal or cytokine exposure. FEBS Lett 560: 103-108, 2004.

7. Dhayal S, Welters HJ and Morgan NG: Structural requirements for the cytoprotective actions of mono-unsaturated fatty acids in the pancreatic beta-cell line, BRIN-BD11. Br J Pharmacol 153: $1718-1727,2008$

8. Dimopoulos N, Watson M, Sakamoto K and Hundal HS: Differential effects of palmitate and palmitoleate on insulin action and glucose utilization in rat L6 skeletal muscle cells. Biochem J 399: 473-481, 2006.

9. Stefan N, Kantartzis K, Celebi N, Staiger H, Machann J, Schick F, Cegan A, Elcnerova M, Schleicher E, Fritsche A and Häring HU: Circulating palmitoleate strongly and independently predicts insulin sensitivity in humans. Diabetes Care 33: 405-407, 2010.

10. Cao H, Gerhold K, Mayers JR, Wiest MM, Watkins SM and Hotamisligil GS: Identification of a lipokine, a lipid hormone linking adipose tissue to systemic metabolism. Cell 134 933-944, 2008.

11. Welters HJ, Diakogiannaki E, Mordue JM, Tadayyon M, Smith SA and Morgan NG: Differential protective effects of palmitoleic acid and cAMP on caspase activation and cell viability in pancreatic beta-cells exposed to palmitate. Apoptosis 11: 1231-1238, 2006.

12. Livak KJ and Schmittgen TD: Analysis of relative gene expression data using real-time quantitative PCR and the 2(-Delta Delta C(T)) Method. Methods 25: 402-408, 2001
13. Liu X, Miyazaki M, Flowers MT, Sampath H, Zhao M, Chu K, Paton CM, Joo DS and Ntambi JM: Loss of Stearoyl-CoA desaturase-1 attenuates adipocyte inflammation: Effects of adipocyte-derived oleate. Arterioscler Thromb Vasc Biol 30: 31-38, 2010.

14. Henquin JC, Ravier MA, Nenquin M, Jonas JC and Gilon P: Hierarchy of the beta-cell signals controlling insulin secretion. Eur J Clin Invest 33: 742-750, 2003.

15. Kotarsky K, Nilsson NE, Flodgren E, Owman C and Olde B: A human cell surface receptor activated by free fatty acids and thiazolidinedione drugs. Biochem Biophys Res Commun 301: 406-410, 2003.

16. Shapiro H, Shachar S, Sekler I, Hershfinkel M and Walker MD: Role of GPR40 in fatty acid action on the beta cell line INS-1E. Biochem Biophys Res Commun 335: 97-104, 2005.

17. Straub SG and Sharp GW: Glucose-stimulated signaling pathways in biphasic insulin secretion. Diabetes Metab Res Rev 18: 451-463, 2002.

18. Graciano MF, Nogueira TC, Carvalho CR, Curi R and Carpinelli AR: Palmitate activites insulin signaling pathway in pancreatic rat islets. Pancreas 38: 578-584, 2009.

19. Gilman AG: G proteins and dual control of adenylate cyclase. Cell 36: 577-579, 1984.

20. Koch WJ, Hawes BE, Allen LF and Lefkowitz RJ: Direct evidence that Gi-coupled receptor stimulation of mitogen-activated protein kinase is mediated by $\mathrm{G}$ beta gamma activation of p21ras. Proc Natl Acad Sci USA 91: 12706-12710, 1994.

21. Adams M, Reginato MJ, Shao D, Lazar MA and Chatterjee VK: Transcriptional activation by peroxisome proliferator-activated receptor gamma is inhibited by phosphorylation at a consensus mitogen-activated protein kinase site. J Biol Chem 272: 5128-5132, 1997.

22. Camp HS and Tafuri SR: Regulation of peroxisome proliferator-activated receptor gamma activity by mitogen-activated protein kinase. J Biol Chem 272: 10811-10816, 1997.

23. Gupta D, Jetton TL, Mortensen RM, Duan SZ, Peshavaria M and Leahy JL: In vivo and in vitro studies of a functional peroxisome proliferator-activated receptor gamma response element in the mouse pdx-1 promoter. J Biol Chem 283: 32462-32470, 2008.

24. Moibi JA, Gupta D, Jetton TL, Peshavaria M, Desai R and Leahy JL: Peroxisome proliferator-activated receptor-gamma regulates expression of PDX-1 and NKX6.1 in INS-1 cells. Diabetes 56: 88-95, 2007. 